Southern Illinois University Edwardsville SPARK

SIUE Faculty Research, Scholarship, and Creative Activity

$4-2016$

\title{
Fipronil Promotes Adipogenesis via AMPKa- mediated Pathway in 3T3-L1 Adipocytes
}

Quancai Sun

University of Massachusetts - Amherst

Jeremy Yang

Amherst Regional High School

Kyong-Sup Yoon

Southern Illinois University Edwardsville, kyoon@siue.edu

John M. Clark

University of Massachusetts - Amherst

Yeonhwa Park

University of Massachusetts - Amherst

Follow this and additional works at: http://spark.siue.edu/siue_fac

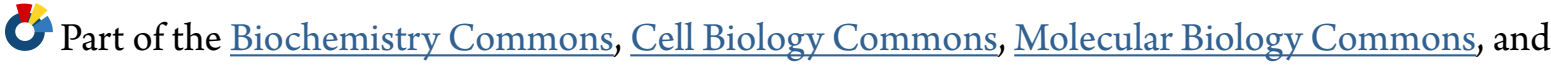
the Toxicology Commons

\section{Recommended Citation}

Sun, Quancai; Yang, Jeremy; Yoon, Kyong-Sup; Clark, John M.; and Park, Yeonhwa, "Fipronil Promotes Adipogenesis via AMPKamediated Pathway in 3T3-L1 Adipocytes" (2016). SIUE Faculty Research, Scholarship, and Creative Activity. 40.

http://spark.siue.edu/siue_fac/40

This Article is brought to you for free and open access by SPARK. It has been accepted for inclusion in SIUE Faculty Research, Scholarship, and Creative Activity by an authorized administrator of SPARK. For more information, please contact gpark@siue.edu. 


\section{Cover Page Footnote}

This is the Accepted Manuscript version of an article published by Elsevier in Food and Chemical Toxicology, available online at http://dx.doi.org/10.1016/j.fct.2016.04.011.

(C) 2013.This manuscript version is made available under the CC-BY-NC-ND 4.0 license http://creativecommons.org/licenses/by-nc-nd/4.0/ 


\section{Accepted Manuscript}

Fipronil promotes adipogenesis via AMPKa-mediated pathway in 3T3-L1 adipocytes

Quancai Sun, Weipeng Qi, Jeremy J. Yang, Kyong Sup Yoon, John M. Clark, Yeonhwa Park

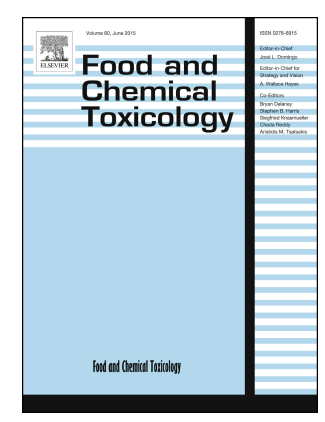

PII:

S0278-6915(16)30117-X

DOI:

10.1016/j.fct.2016.04.011

Reference: $\quad$ FCT 8561

To appear in: Food and Chemical Toxicology

Received Date: 21 January 2016

Revised Date: 23 March 2016

Accepted Date: 15 April 2016

Please cite this article as: Sun, Q., Qi, W., Yang, J.J., Yoon, K.S., Clark, J.M., Park, Y., Fipronil promotes adipogenesis via AMPKa-mediated pathway in 3T3-L1 adipocytes, Food and Chemical Toxicology (2016), doi: 10.1016/j.fct.2016.04.011.

This is a PDF file of an unedited manuscript that has been accepted for publication. As a service to our customers we are providing this early version of the manuscript. The manuscript will undergo copyediting, typesetting, and review of the resulting proof before it is published in its final form. Please note that during the production process errors may be discovered which could affect the content, and all legal disclaimers that apply to the journal pertain. 


\title{
Fipronil promotes adipogenesis via AMPKa-mediated pathway in 3T3-L1 adipocytes
}

\author{
Quancai Sun ${ }^{1}$, Weipeng Qi ${ }^{1}$, Jeremy J. Yang ${ }^{2}$, Kyong Sup Yoon ${ }^{3}$, John M. Clark ${ }^{4}$, \\ and Yeonhwa Park ${ }^{1, *}$ \\ ${ }^{1}$ Department of Food Science, and ${ }^{4}$ Department of Veterinary and Animal Sciences, University \\ of Massachusetts, Amherst, MA, 01003, United States, \\ ${ }^{2}$ Amherst Regional High School, Amherst, MA, 01003, United States \\ ${ }^{3}$ Department of Biological Sciences and Environmental Sciences Program, Southern Illinois \\ University, Edwardsville, IL 62026, United States
}

*To whom correspondence should be addressed

Department of Food Science, University of Massachusetts

102 Holdsworth Way, Amherst, MA 01003

Telephone: (413) 545-1018, Fax: (413) 545-1262; e-mail: ypark@foodsci.umass.edu 


\begin{abstract}
Emerging evidence suggests that organochlorine, organophosphorus and neonicotinoid insecticide exposure may be linked to the development of obesity and type 2 diabetes. However, there is no knowledge of the potential influence of fipronil, which belongs to the phenylpyrazole chemical family, on obesity. Thus, the goal of this study was to determine the role of fipronil in adipogenesis using 3T3-L1 adipocytes. Fipronil treatment, at $10 \mu \mathrm{M}$, increased fat accumulation in 3T3-L1 adipocytes as well as promoted key regulators of adipocyte differentiation (CCAAT/enhancer-binding protein $\alpha$ and peroxisome proliferator-activated receptor gamma- $\gamma$ ), and key regulators of lipogenesis (acetyl-CoA carboxylase and fatty acid synthase). The activation of AMPK $\alpha$ with 5-aminoimidazole-4-carboxamide ribonucleotide (AICAR) abolished effects of fipronil on increased adipogenesis. These results suggest that fipronil alters adipogenesis and results in increased lipid accumulation through a AMPK $\alpha$-mediated pathway.
\end{abstract}

Keywords: fipronil, phenylpyrazole, lipid metabolism, adipogenesis, AMPK $\alpha$. 


\section{Introduction}

Fipronil (5-amino-1-[2, 6-dichloro-4-(trifluoromethyl) phenyl]-4-[(trifluoromethyl) sulfinyl]-1Hpyrazole-3-carbonitrile) is one of the important broad spectrum insecticides used for the control of arthropod pests, which threaten agricultural yields and the health of humans and other animal species (Dryden et al., 2000). As a phenylpyrazole compound, fipronil's action is attributable to the potent, antagonistic action at the neurotransmitter gamma-aminobutyric acid (GABA) receptor. In addition, fipronil disrupts the insect nervous system by blocking both GABA-gated chloride and glutamate-gated chloride (GluCl) channels (Raymond-Delpech et al., 2005). Given that fipronil has a higher binding affinity to insect GABA receptors, and mammals do not have glutamate-gated chloride channels, fipronil has a selective toxicity towards insects compared to mammals (Hainzl and Casida, 1996; Hainzl et al., 1998).

Fipronil is known to be degraded in the environment through photolysis, oxidation, and reduction. It is reported that fipronil is more susceptible to photolysis (half life, $\sim 8 \mathrm{hr}$ ) than hydrolysis (half life, > 100 days) in water at pH 5 (Troung, 2007). Interestingly, desulfinyl fipronil, a primary photolysis product of fipronil, has approximately 10 -fold higher affinity for mammalian GABA receptors than the parent fipronil and substantially reduces selectivity between insects and mammals (Hainzl et al., 1998). As fipronil has been formulated into a variety of products, such as solid insect baits, liquid sprays, and a granular products, it has been used to control a broad range of arthropod pests, including the boll weevil, grasshoppers, plant hoppers, ants, cockroaches, termites, fleas and ticks (Tingle et al., 2000). This wide range of usage makes animal and human exposure to fipronil nearly unavoidable and fipronil is categorized as a pesticide of concern for metabolic disorders (Level 3), which needs to be particularly monitored (Bonmatin et al., 2015; Nougadere et al., 2011). Based on previous 
publications on the relationships between exposure to insecticides and obesity, including our previous reports of other types of insecticides promoting adipogenesis in 3T3-L1 adipocytes (Kim et al., 2014; Kim et al., 2016; Lassiter and Brimijoin, 2008; Lassiter et al., 2008; Lee et al., 2006; Lee et al., 2011; Longnecker and Daniels, 2001; Mangum et al., 2015; Park et al., 2013), we presently determine the role of fipronil in adipogenesis using the 3T3-L1 adipocyte model.

\section{Materials and Methods}

\subsection{Materials}

3T3-L1 preadipocytes were obtained from American Type Culture Collection (Manassas, VA). Fetal bovine serum (FBS), Dulbecco's modified Eagle's medium (DMEM), methylisobutylxanthin, insulin, dexamethasone, dimethyl sulfoxide (DMSO), 5-aminoimidazole4-carboxamide ribonucleotide (AICAR), and fipronil were purchased from Sigma-Aldrich Co. (St. Louis, MO). The contents of triglyceride and protein were quantified using kits from Thermo Scientifics (Middletown, VA) and Bio-Rad Co. (Hercules, CA), respectively. Trizol was bought from Thermo Scientific (Rockford, IL) and other chemicals were purchased from Fisher Scientific (Pittsburgh, PA). Radioimmunoprecipitation assay (RIPA) buffer supplemented with $1 \%$ protease inhibitor was purchased from Boston Bioproducts Inc. (Ashland, MA).

\subsection{T3-L1 Culture}

3T3-L1 preadipocytes were cultured as described in a previous paper (Park et al., 2013). 3T3-L1 preadipocytes were maintained in DMEM with $10 \% \mathrm{FBS}$ at $37{ }^{\circ} \mathrm{C}$ until confluence. 2 days after confluence (day 0), adipocyte differentiation was induced with DMEM containing 10\% FBS and a mixture of methylisobutylxanthin $(0.5 \mathrm{mM})$, dexamethasone $(1 \mu \mathrm{M})$, and insulin $(1 \mu \mathrm{g} / \mathrm{mL})$. On 
day 2, the medium was changed to DMEM containing $10 \%$ FBS and insulin only. From day 4, cells were maintained in DMEM plus 10\% FBS, and the medium was changed at 2-day intervals. Cells were treated with fipronil $(0.1,1$, and $10 \mu \mathrm{M})$ or AICAR $(40 \mu \mathrm{M})$ from day 0 as indicated in each figure legend. Fipronil (100 mM) and AICAR (0.4 M) stock solutions were prepared in DMSO. Previously, AICAR concentrations at 250 and 1,000 $\mu \mathrm{M}$ were used in 3T3-L1 adipocytes (Habinowski and Witters, 2001). We tested various concentrations of AICAR (40$500 \mu \mathrm{M})$ and determined that $40 \mu \mathrm{M}$ was appropriate to use without influences on cell viability based on the 3-(4,5-dimethylthiazolyl-2)-2, 5-diphenyltetrazolium bromide (MTT) assay (data not shown) (Mosmann, 1983). Control was treated with DMSO and all treatments had DMSO at a final concentration of $0.02 \%$. We didn't observe any influences of fipronil concentrations used in the current study on cell viability measured by a MTT based assay method (data not shown).

\subsection{Triglyceride quantification}

Cells were washed with phosphate-buffered saline (PBS) and harvested by scraping in PBS containing $1 \%$ Triton-X after 8 days of differentiation. Homogenous samples were obtained from cells by sonication. The amount of triglyceride (TG) in the samples was measured with a commercial assay kit (Infinity ${ }^{\mathrm{TM}}$ Triglycerides Reagent; Thermo Scientific) and the protein content was measured with Bio-Rad DC protein assay kit according to manufacturer's instructions. TG content was normalized with protein concentration.

\section{4. mRNA expression analysis}

Trizol reagent was used to extract total RNA from cells under RNase free conditions. Total RNA was reverse-transcribed with Moloney murine leukemia virus (M-MLV) reverse transcriptase 
(high-capacity reverse transcription kit, Applied Biosystems). mRNA expression levels of CCAAT/enhancer-binding protein $\alpha(\mathrm{C} / \mathrm{EBP} \alpha)$, peroxisome proliferator-activated receptor gamma (PPAR- $\gamma$ ), acetyl-CoA carboxylase (ACC), fatty acid synthase (FAS), fatty acid binding protein 4 (FABP4), adipose triglyceride lipase (ATGL), glucose transporter 4 (GLUT4), and leptin were analyzed from 3T3-L1 adipocytes. Real-time polymerase chain reaction (PCR) was performed on a StepOne Plus real time PCR instrument (Applied Biosystems, Carlsbad, CA) and Taqman probe-based gene expression analysis (Applied Biosystems, Carlsbad, CA). Respective integrated sequences for Taqman gene expression were NM_007678.3 (C/EBP $\alpha$ ), NM_001127330.2 (PPAR- $\gamma$ ), NM_133360.2, NM_007988.3 (FAS), NM_024406.2 (FABP4), NM_001163689 (ATGL), NM_009204.2 (GLUT4), and NM_008493.3 (leptin), with glyceraldehyde-3-phosphate dehydrogenase (GAPDH, NM_008084.2) as an internal standard.

\subsection{Immunoblotting}

Cells were lysed with RIPA buffer supplemented with phosphatase inhibitor cocktail and protease inhibitor cocktail (Thermo Scientific, Rockford, IL). Protein concentrations were determined using the protein DC assay kit (Bio-Rad Co., Hercules, CA). Cell lysates containing $50 \mu \mathrm{g}$ of protein were separated with $6 \%$ or $10 \%$ SDS-polyacrylamide gel and transferred to Immobilin P membrane (Millipore, Bedford, MA). Primary rabbit antibodies were diluted following the recommendation of producers. $\beta$-actin was used as an internal control. Horseradish peroxidase conjugated goat anti-rabbit IgG was used as the secondary antibody. Detections were performed on an image Station 4000MM (Carestream Health, New Haven, CT) with Clarity ${ }^{\mathrm{TM}}$ Western ECL Substrate Kit (Bio-Rad Co., Hercules, CA). Image and results were quantified with Image J software (Schneider et al., 2012). 


\subsection{Statistical analyses}

Data in Figures 2-4 were analyzed by the one-way analysis of variance procedure (ANOVA) using the Statistical Analysis System (SAS Institute, Cary, NC). Data in Figure 1 were analyzed by the two-way ANOVA with PROC MIXED option. Tukey's multiple-range test was used to determine significant differences between treatments. Significance of differences was defined at the $p<0.05$ level.

\section{Results}

\subsection{Fipronil significantly increased lipid accumulation in 3T3-L1 adipocytes}

Figure 1 shows effects of fipronil on lipid accumulation in 3T3-L1 adipocytes. Fipronil $(10 \mu \mathrm{M})$ treatment significantly increased TG content compared to control $(p<0.001)$, but not at lower concentrations, in this model.

\subsection{Influence of fipronil on adipogenesis}

Figure 2 shows influence of fipronil on genes regulating adipocyte differentiation and lipid metabolism. Treatment with fipronil $(10 \mu \mathrm{M})$ significantly increased expression of two key genes involved in adipocyte differentiation, CCAAT/enhancer-binding protein $\alpha(\mathrm{C} / \mathrm{EBP} \alpha$, $p<0.01)$ and peroxisome-proliferator activated receptor- $\gamma(\operatorname{PPAR} \gamma, p<0.0001)$, compared to control (Fig. 2A and 2B). Fipronil $(10 \mu \mathrm{M})$ also significantly increased expression of two ratelimiting enzymes for lipogenesis, fatty acid synthase (FAS, Fig. 2C) and acetyl Co-A carboxylase (ACC, Fig. 2D), compared to control. Expression of fatty acid-binding protein 4 (FABP4), a protein transporting fatty acids in cytoplasm for metabolic process or storage (Terra 
et al., 2011), was likewise increased significantly by $10 \mu \mathrm{M}$ fipronil treatment compared to control (Fig. 2E, $p<0.0001$ ). These results show that fipronil promoted adipocyte differentiation and lipogenesis, contributing to increased lipid accumulation at $10 \mu \mathrm{M}$.

Expression of glucose transporter 4 (GLUT4), a 12 trans-membrane protein that plays a major role in insulin mediated glucose transport in adipocytes (Huang and Czech, 2007), was also significantly increased following $10 \mu \mathrm{M}$ fipronil treatment compared to control (Fig. 2F, $p<0.0001)$. This finding suggests that fipronil may have altered glucose metabolism, which also contributes to increased lipid accumulation in this model. Fipronil treatment, up to $10 \mu \mathrm{M}$, did not affect expression of leptin and adipose triglyceride lipase (ATGL) (Fig. 2G and 2H), which are known to correlate with obesity (Garfinkel et al., 1967 ; Holm et al., 2000).

\subsection{Effects of fipronil on the protein expression of regulators for adipogenesis}

We further investigated the influence of fipronil on the protein expression of key regulators of adipogenesis (Fig. 3). Compared to control, fipronil $(10 \mu \mathrm{M})$ treatment significantly increased the protein expression of $\mathrm{C} / \mathrm{EBP} \alpha$ (Fig. 3B) and PPAR $\gamma$ (Fig. 3C). AMPK $\alpha$ is a master regulator of energy production and lipid metabolism in the cell (Park et al., 2002). Fipronil (10 $\mu$ M) treatment decreased the phosphorylation of AMPK $\alpha$ significantly compared to control, without affecting the total levels of AMPK $\alpha$ (Fig. 3D, 3E and 3F). These results indicate reduced activation of AMPK $\alpha$ by fipronil. Expression of ACC (active form), a downstream target of AMPK $\alpha$, was increased significantly, while phosphorylation of ACC (inactive form) was decreased significantly by fipronil treatment compared to control (Fig. 3G, 3H and 3I). These findings suggest that fipronil may regulate adipogenesis by inhibiting post-translational regulation of AMPKo in 3T3-L1 cells. 


\subsection{Effect of AMPKa activation on adipogenesis by fipronil}

Next, we investigated whether AMPK activation could inhibit enhanced adipogenesis induced by fipronil using a combination treatment of AICAR, an AMPK activator, and fipronil (Fig. 4). AICAR is an adenosine analogue, which is taken up by adenosine transporters on the cell membrane and then is phosphorylated to generate 5-amino-4-imidazolecarboxamide ribotide (ZMP). ZMP mimics AMP, thus, stimulates AMPK phosphorylation in the cell (Merrill et al., 1997). As shown in Fig. 4, AICAR treatment alone decreased fat accumulation $(p<0.0001$ compared to control), while $10 \mu \mathrm{M}$ fipronil treatment alone significantly increased fat accumulation as observed in results in Fig. 3. When cells were treated with AICAR and fipronil together, the fat accumulation decreased significantly compared to fipronil treatment alone and control $(p<0.0001$ for both $)$.

\subsection{Influence of AMPKa activation on protein expression of regulators for adipogenesis}

Figure 5 shows protein expression of regulators of adipogenesis when AICAR and fipronil were co-treated. As expected, AICAR treatment alone significantly decreased the expression of $\mathrm{C} / \mathrm{EBP} \alpha, \mathrm{ACC}$, while increased the expressions of $\mathrm{pAMPK} \alpha$ and $\mathrm{pACC}$, compared to controls. When cells were treated together with fipronil and AICAR, the protein expression of C/EBP $\alpha$, ACC decreased significantly compared to fipronil treatment alone ( $p<0.0001$ for both). AICAR and fipronil co-treatment also significantly increased the protein expression of pAMPK $\alpha, \mathrm{pACC}$, as well as the ratio of $\mathrm{pAMPK} \alpha / \mathrm{AMPK} \alpha$ and $\mathrm{pACC} / \mathrm{ACC}(p<0.001)$, compared to fipronil treatment alone. These results suggest that AMPK $\alpha$ activation could abolish enhanced adipogenesis induced by fipronil. 


\section{Discussion}

Results from the current study suggest that fipronil exposure contributes to increased adipogenesis in 3T3-L1 cell model. To our knowledge, this is the first report linking enhanced adipogenesis to fipronil, particularly at $10 \mu \mathrm{M}$. We further expand our understanding that AMPK $\alpha$ pathway is involved in increased adipogenesis induced by fipronil.

AMPK is the downstream component of a protein kinase cascade that has a central role in the regulation of energy balance and lipid metabolism (Bijland et al., 2013). Activation of AMPK has been suggested to inhibit adipogenesis with reduced expression of PPAR $\gamma, \mathrm{C} / \mathrm{EBP} \alpha$ and late adipogenic markers such as FAS and ACC (Habinowski and Witters, 2001). Activation of AMPK has also been reported to inhibit lipogenesis by phosphorylation of ACC, the key regulated step in fatty acid synthesis and fatty acid oxidation. ACC catalyzes the synthesis of malonyl-CoA, a substrate of fatty acid synthesis, and is inhibited by AMPK-mediated phosphorylation of ACC (Daval et al., 2005). Our current results suggest that fipronil may influence lipid metabolism via post-translational regulation of AMPK. With the current results, it is not clear if fipronil directly or indirectly targets AMPK. However, fipronil has previously been reported to increase intracellular $\mathrm{Ca}^{2+}$ levels, by alteration of the permeabilization of plasma membrane induced by fipronil (Trump and Berezesky, 1992). Based on reports that chronic elevation of intracellular calcium might impair the activation of AMPK, via calcium/calmodulin kinase kinase- $\beta$ (CaMKK $\beta$ ) (Gormand et al., 2011 ; Park et al., 2009), it is possible that fipronil may influence intracellular calcium levels and lead to altered adipogenesis and lipid metabolism via CaMKK $\beta$-and AMPK- mediated mechanisms. However, fipronil's effect on intracellular calcium needs to be further confirmed in the future. 
In the current study, no significant differences of leptin mRNA were found between control and fipronil treatment groups in this model. Although we did not measure leptin secretion in this study, it is known that expression of leptin is well correlated to leptin secretion in the 3T3L1 model (Slieker et al., 1998). Previously, Lassiter and Brimijoin (Lassiter and Brimijoin, 2008) reported that organophosphorus insecticide treatment could impair leptin production. Two previous publications from our group consistently reported that imidacloprid and permethrin had no effect on leptin expression, which suggests impaired leptin production by these insecticides (Kim et al., 2014 ; Lassiter and Brimijoin, 2008 ; Park et al., 2013). Thus, the lack of effects of fipronil on leptin expression might be in part due to impaired leptin signaling by fipronil treatment. This may also contribute to altered lipid accumulation, as leptin plays an important role in regulating food intake and glucose metabolism (Morton and Schwartz, 2011).

The toxicity symptoms of fipronil in mice include hyperactivity, irritability, and convulsions, leading to death (Dobozy, 2000 ; Hamernik, 1997). Moreover, recently it was suggested that fipronil induces specific liver enzymes, which may have significant implication on interactions with xenobiotics as well as endogenous compounds (Caballero et al., 2015). The oral $\mathrm{LD}_{50}$ of fipronil in rat being $97 \mathrm{mg} / \mathrm{kg}$ body weight (Dobozy, 2000 ; Hamernik, 1997). The ADI (acceptable daily intake) of fipronil was determined to be $0.0002 \mathrm{mg} / \mathrm{kg}$ body weight, based on the oral NOAEL (no observed adverse effect level) of $0.019 \mathrm{mg} / \mathrm{kg}$ body weight/day in a 2year study of toxicity and carcinogenicity in rats (Dobozy, 2000 ; Hamernik, 1997). The major metabolite of fipronil detected in adipose tissue, liver, kidney, and muscle of rat was the fipronil sulfone, while two main metabolites, fipronil sulfone and fipronil amide, were found in urine (Dobozy, 2000 ; Hamernik, 1997). In a pharmacokinetics study of fipronil in rats using ${ }^{14} \mathrm{C}$ fipronil administered orally at a single dose of $4 \mathrm{mg} / \mathrm{kg}$ body weight, the radioactivity in blood 
reached a maximum value 5.5 hours after treatment and decreased thereafter, with an elimination half-life of 183 hours. The relative long half-life suggests the bioaccumulation of metabolic products from fipronil may have occurred in adipose tissue (Hamernik, 1997). In fact, the highest concentration of fipronil sulfone in adipose tissue reported was $31 \mathrm{ppm}$, which is equivalent to $\sim 70 \mu \mathrm{M}$ (Dobozy, 2000 ; Hamernik, 1997).

Currently, only limited information exists concerning the serum levels of fipronil in humans. One occupational exposure study of workers at a fipronil production facility reported fipronil sulfone serum level of $17.8 \mathrm{nM}$, although the levels of fipronil or its metabolites in adipose tissue levels were not measured (Herin et al., 2011). The plasma levels of total fipronil (including its metabolites) in patients who were orally exposed to fipronil ranged from 0.12 to $9.15 \mu \mathrm{M}$ (Mohamed et al., 2004). Thus, levels of fipronil used in the present study were higher than potential exposure levels for most populations. Nevertheless, based on observation that fipronil and its metabolites bioaccumulate in adipose tissue $(\sim 70 \mu \mathrm{M})$ (Dobozy, 2000 ; Hamernik, 1997), the findings of the current study may have significant implication on biological relevance of fipronil on adipogenesis.

In comparison to the biological fate of fipronil above, it is also known to be degraded in the environment through photolysis, oxidation, and reduction (Troung, 2007). Fipronil is particularly sensitive to photolysis with half-life of $\sim 8 \mathrm{hr}$, resulting in desulfinyl fipronil as the primary photolysis product (Hainzl et al., 1998). This metabolite has a 10-fold higher affinity for mammalian GABA receptors than parent fipronil and reduces selectivity substantially between insects and mammals (Hainzl et al., 1998). Thus, it is also important to determine the potential role of metabolites of fipronil from both biological and environmental systems. 
To summarize, our present finding reports the influence of fipronil on enhanced adipocyte differentiation and increased fat accumulation in adipocytes and are significant in providing a potential link between insecticide exposure, particularly fipronil, and impaired adipocyte functions. Nonetheless, our current results are limited to an in vitro model using relatively high doses of fipronil. In addition, the role of fipronil metabolites still needs to be determined. Thus, further in vivo studies of fipronil, as well as epidemiological studies, are necessary to further elucidate the significance of the current study.

\section{Acknowledgements}

There is no conflict of interest associated with authors in this manuscript.

The China Scholarship Council supported Mr. Sun. 


\section{References}

Bijland, S., Mancini, Sarah J., Salt, Ian P., 2013. Role of AMP-activated protein kinase in adipose tissue metabolism and inflammation. Clin. Sci. 124, 491-507.

Bonmatin, J.M., Giorio, C., Girolami, V., Goulson, D., Kreutzweiser, D.P., Krupke, C., Liess, M., Long, E., Marzaro, M., Mitchell, E.A.D., Noome, D.A., Simon-Delso, N., Tapparo, A., 2015. Environmental fate and exposure; neonicotinoids and fipronil. Environ. Sci. Pollut. R. 22, $35-67$.

Caballero, M.V., Ares, I., Martínez, M., Martínez-Larrañaga, M.R., Anadón, A., Martínez, M.A., 2015. Fipronil induces CYP isoforms in rats. Food Chem. Toxicol. 83, 215-221.

Daval, M., Diot-Dupuy, F., Bazin, R., Hainault, I., Viollet, B., Vaulont, S., Hajduch, E., Ferre, P., Foufelle, F., 2005. Anti-lipolytic action of AMP-activated protein kinase in rodent adipocytes. J. Biol. Chem. 280, 25250-25257.

Dobozy, V.A., 2000. Pesticide residues in food 2000 : FIPRONIL (addendum). http://www.inchem.org/documents/jmpr/jmpmono/v00pr07.htm.

Dryden, M.W., Denenberg, T.M., Bunch, S., 2000. Control of fleas on naturally infested dogs and cats and in private residences with topical spot applications of fipronil or imidacloprid. Vet. Parasitol. 93, 69-75.

Garfinkel, A.S., Baker, N., Schotz, M.C., 1967. Relationship of lipoprotein lipase activity to triglyceride uptake in adipose tissue. J. Lipid Res. 8, 274-280.

Gormand, A., Henriksson, E., Strom, K., Jensen, T.E., Sakamoto, K., Goransson, O., 2011. Regulation of AMP-activated protein kinase by LKB1 and CaMKK in adipocytes. J. Cell Biochem. 112, 1364-1375.

Habinowski, S.A., Witters, L.A., 2001. The effects of AICAR on adipocyte differentiation of 3T3-L1 cells. Biochem. Biophys. Res. Commun. 286, 852-856.

Hainzl, D., Casida, J.E., 1996. Fipronil insecticide: Novel photochemical desulfinylation with retention of neurotoxicity. P. Natl. Acad. Sci. USA 93, 12764-12767.

Hainzl, D., Cole, L.M., Casida, J.E., 1998. Mechanisms for selective toxicity of fipronil insecticide and its sulfone metabolite and desulfinyl photoproduct. Chem. Res. Toxicol. 11, 1529-1535.

Hamernik, K.L., 1997. Pesticide residues in food - 1997.

http://www.inchem.org/documents/jmpr/jmpmono/v097pr09.htm 
Herin, F., Boutet-Robinet, E., Levant, A., Dulaurent, S., Manika, M., Galatry-Bouju, F., Caron, P., Soulat, J.M., 2011. Thyroid function tests in persons with occupational exposure to fipronil. Thyroid : official journal of the American Thyroid Association 21, 701-706.

Holm, C., Osterlund, T., Laurell, H., Contreras, J.A., 2000. Molecular mechanisms regulating hormone-sensitive lipase and lipolysis. Annu. Rev. Nutr. 20, 365-393.

Huang, S., Czech, M.P., 2007. The GLUT4 glucose transporter. Cell Metab. 5, 237-252.

Kim, J., Park, Y., Yoon, K.S., Clark, J.M., Park, Y., 2014. Permethrin alters adipogenesis in 3T3-L1 adipocytes and causes insulin resistance in $\mathrm{C} 2 \mathrm{C} 12$ myotubes. J. Biochem. Mol. Toxicol. $28,418-424$.

Kim, J., Sun, Q., Yue, Y., Yoon, K.S., Whang, K.-Y., Clark, J.M., Park, Y., 2016. 4, 4' dichlorodiphenyltrichloroethane (DDT) and 4, 4' -dichlorodiphenyldichloroethylene (DDE) promote adipogenesis in 3TL1 adipocyte cell culture. Pesticide Biochemistry and Physiology.

Lassiter, T.L., Brimijoin, S., 2008. Rats gain excess weight after developmental exposure to the organophosphorothionate pesticide, chlorpyrifos. Neurotoxicol. Teratol. 30, 125-130.

Lassiter, T.L., Ryde, I.T., Mackillop, E.A., Brown, K.K., Levin, E.D., Seidler, F.J., Slotkin, T.A., 2008. Exposure of neonatal rats to parathion elicits sex-selective reprogramming of metabolism and alters the response to a high-fat diet in adulthood. Environ. Health Persp. 116, 1456-1462.

Lee, D.H., Jacobs, D.R., Porta, M., 2006. Could low-level background exposure to persistent organic pollutants contribute to the social burden of type 2 diabetes? J. Epidemiol. Community Health 60, 1006-1008.

Lee, D.H., Steffes, M.W., Sjodin, A., Jones, R.S., Needham, L.L., Jacobs, D.R., Jr., 2011. Low dose organochlorine pesticides and polychlorinated biphenyls predict obesity, dyslipidemia, and insulin resistance among people free of diabetes. PloS one 6, e15977.

Longnecker, M.P., Daniels, J.L., 2001. Environmental contaminants as etiologic factors for diabetes. Environ. Health Persp. 109, 871-876.

Mangum, L.H., Howell, G.E., 3rd, Chambers, J.E., 2015. Exposure to p,p'-DDE enhances differentiation of 3T3-L1 preadipocytes in a model of sub-optimal differentiation. Toxicol. Lett. $238,65-71$.

Merrill, G.F., Kurth, E.J., Hardie, D.G., Winder, W.W., 1997. AICA riboside increases AMPactivated protein kinase, fatty acid oxidation, and glucose uptake in rat muscle. Am. J. Physiol. 273, E1107-1112.

Mohamed, F., Senarathna, L., Percy, A., Abeyewardene, M., Eaglesham, G., Cheng, R., Azher, S., Hittarage, A., Dissanayake, W., Sheriff, M.H., Davies, W., Buckley, N.A., Eddleston, M., 2004. Acute human self-poisoning with the N-phenylpyrazole insecticide fipronil--a GABAAgated chloride channel blocker. J. Toxicol. Clin. Toxicol. 42, 955-963. 
Morton, G.J., Schwartz, M.W., 2011. Leptin and the central nervous system control of glucose metabolism. Physiol. Rev. 91, 389-411.

Mosmann, T., 1983. Rapid colorimetric assay for cellular growth and survival: Application to proliferation and cytotoxicity assays. Journal of immunological methods 65, 55-63.

Nougadere, A., Reninger, J.C., Volatier, J.L., Leblanc, J.C., 2011. Chronic dietary risk characterization for pesticide residues: a ranking and scoring method integrating agricultural uses and food contamination data. Food Chem Toxicol 49, 1484-1510.

Park, S., Scheffler, T.L., Gunawan, A.M., Shi, H., Zeng, C., Hannon, K.M., Grant, A.L., Gerrard, D.E., 2009. Chronic elevated calcium blocks AMPK-induced GLUT-4 expression in skeletal muscle. Am. J. Physiol. Cell Physiol. 296, C106-115.

Park, S.H., Gammon, S.R., Knippers, J.D., Paulsen, S.R., Rubink, D.S., Winder, W.W., 2002. Phosphorylation-activity relationships of AMPK and acetyl-CoA carboxylase in muscle. J. Appl. Physiol (1985). 92, 2475-2482.

Park, Y., Kim, Y., Kim, J., Yoon, K.S., Clark, J., Lee, J., Park, Y., 2013. Imidacloprid, a neonicotinoid insecticide, potentiates adipogenesis in 3T3-L1 adipocytes. J. Agric. Food Chem. $61,255-259$.

Raymond-Delpech, V., Matsuda, K., Sattelle, B.M., Rauh, J.J., Sattelle, D.B., 2005. Ion channels: molecular targets of neuroactive insecticides. Invert Neurosci. 5, 119-133.

Schneider, C.A., Rasband, W.S., Eliceiri, K.W., 2012. NIH Image to ImageJ: 25 years of image analysis. Nature methods 9, 671-675.

Slieker, L.J., Sloop, K.W., Surface, P.L., 1998. Differentiation method-dependent expression of leptin in adipocyte cell lines. Biochem. Biophys. Res. Commun. 251, 225-229.

Terra, X., Quintero, Y., Auguet, T., Porras, J.A., Hernandez, M., Sabench, F., Aguilar, C., Luna, A.M., Del Castillo, D., Richart, C., 2011. FABP 4 is associated with inflammatory markers and metabolic syndrome in morbidly obese women. Eur. J. Endocrinol. 164, 539-547.

Tingle, C., Rother, J., Dewhurst, C., Lauer, S., King, W., 2000. Health and environmental effects of fipronil. Briefing paper for Pesticides Action Network, UK.

Troung, A.S.G.a.T., 2007. Environmental Fate of Fipronil.

http://cdpr.ca.gov/docs/emon/pubs/fatememo/fipronilrev.pdf California Environmental

Protection Agency.

Trump, B.F., Berezesky, I.K., 1992. The role of cytosolic Ca2+ in cell injury, necrosis and apoptosis. Curr. Opin. Cell Biol. 4, 227-232. 
Figure 1. Fipronil treatment increased triglyceride accumulation in 3T3-L1 adipocytes. Cells were treated with fipronil for 8 days. Numbers are mean \pm S.E. $(n=10-12$, from 3 independent experiments). Means with different letters were significantly different at $p<0.01$.

Figure 2. Effects of fipronil on gene expression of molecular mediators of adipogenesis.

A. C/EBP- $\alpha$, CAATT element binding protein- $\alpha$; B. PPAR $\gamma$, Peroxisome proliferator-activated receptor gamma; C. FAS, Fatty acid synthase; D. ACC, Acetyl-CoA carboxylase; E. FABP4, Fatty acid binding protein 4; F. GLUT4, Glucose transporter type 4; G. Leptin; H. ATGL, Adipose triglyceride lipase. Numbers represent mean \pm S.E. $(n=4-6)$. Means with different letters were significantly different at $p<0.05$, except $2 \mathrm{~A}(p<0.01) ; 2 \mathrm{~B}, 2 \mathrm{E} \& 2 \mathrm{~F}(p<0.0001)$

Figure 3. Effects of fipronil on protein levels of molecular mediators of adipogenesis. B. C/EBP$\alpha$, CAATT element binding protein- $\alpha$; C. PPAR- $\gamma$, peroxisome proliferator-activated receptor- $\gamma$; D. AMPK $\alpha$, AMP-activated protein kinase- $\alpha$ (inactive form); E. pAMPK $\alpha$, phosphorylated AMPK $\alpha$ (active form), G. ACC, acetyl-CoA carboxylase (active form); H. pACC, phosphorylated ACC (inactive form). Cells were treated with fipronil for 8 days. Numbers represent mean \pm S.E. $(\mathrm{n}=3)$. Means with different letters were significantly different at $p<0.05$.

Figure 4. AICAR (5-Aminoimidazole-4-carboxamide ribonucleotide) abolished the increased fat accumulation induced by fipronil. Cells were treated with fipronil $(10 \mu \mathrm{M})$ or AICAR (40 $\mu \mathrm{M})$ for 8 days. Numbers represent mean \pm S.E. $(n=3)$. Means with different letters were significantly different at $p<0.05$. 
Figure 5. AICAR (5-Aminoimidazole-4-carboxamide ribonucleotide) abolished the increased expression of $\mathrm{C} / \mathrm{EBP} \alpha, \mathrm{ACC}$ and the decreased expression of $\mathrm{pAMPK} \alpha, \mathrm{pACC}$ induced by fipronil. B. C/EBP- $\alpha$, CAATT element binding protein- $\alpha$; C. AMPK $\alpha$, AMP-activated protein kinase- $\alpha$; D. pAMPK $\alpha$, phosphorylated AMPK $\alpha$ (active form); F. ACC, acetyl-CoA carboxylase (active form); G. pACC, phosphorylated ACC (inactive form). Cells were treated with fipronil $(10 \mu \mathrm{M})$ or AICAR $(40 \mu \mathrm{M})$ for 8 days. Numbers represent mean \pm S.E. $(\mathrm{n}=3-4)$. Means with different letters were significantly different at $p<0.05$, except $5 \mathrm{~F}(p<0.01)$. 


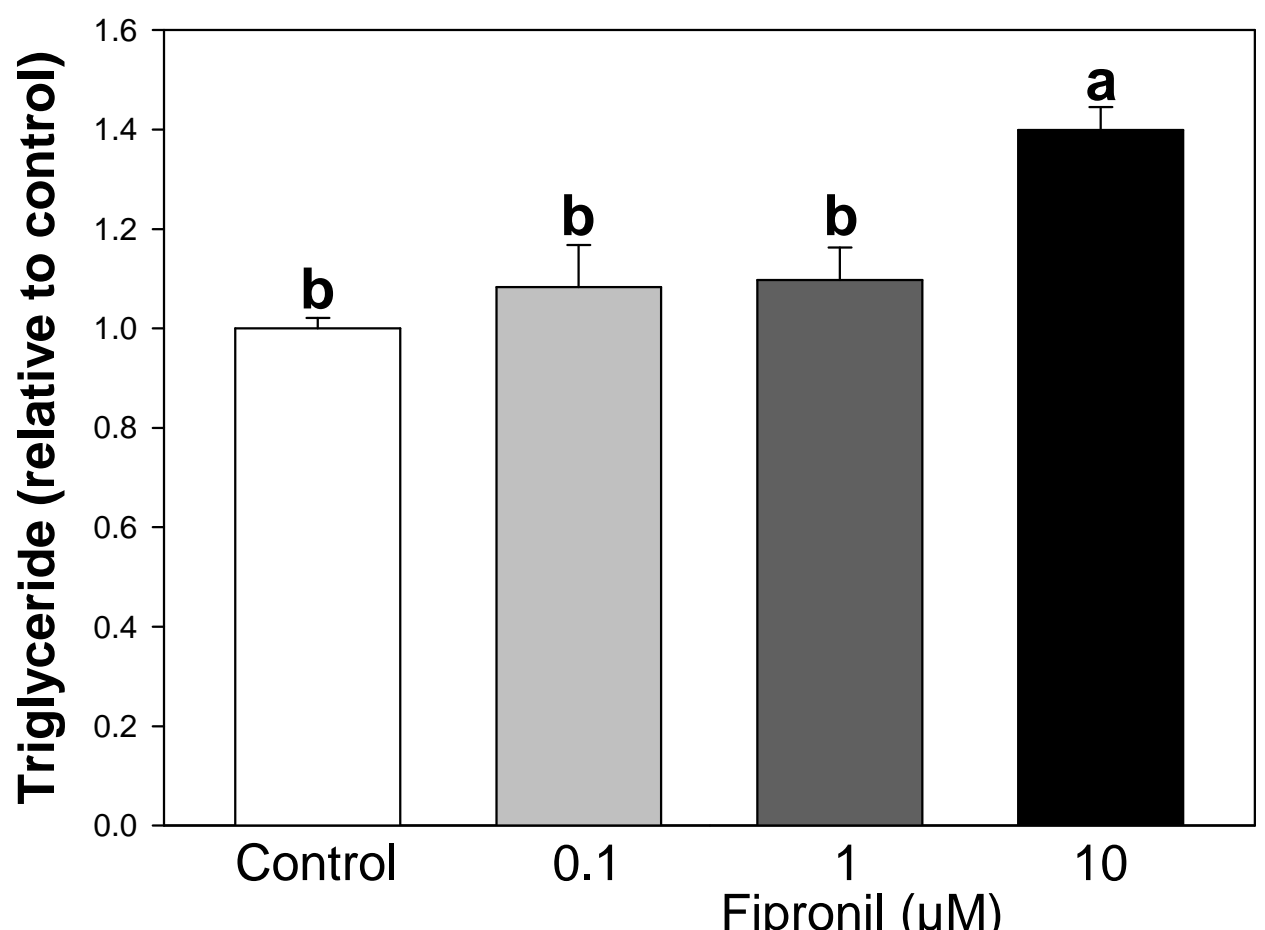

Fipronil $(\mu \mathrm{M})$ 

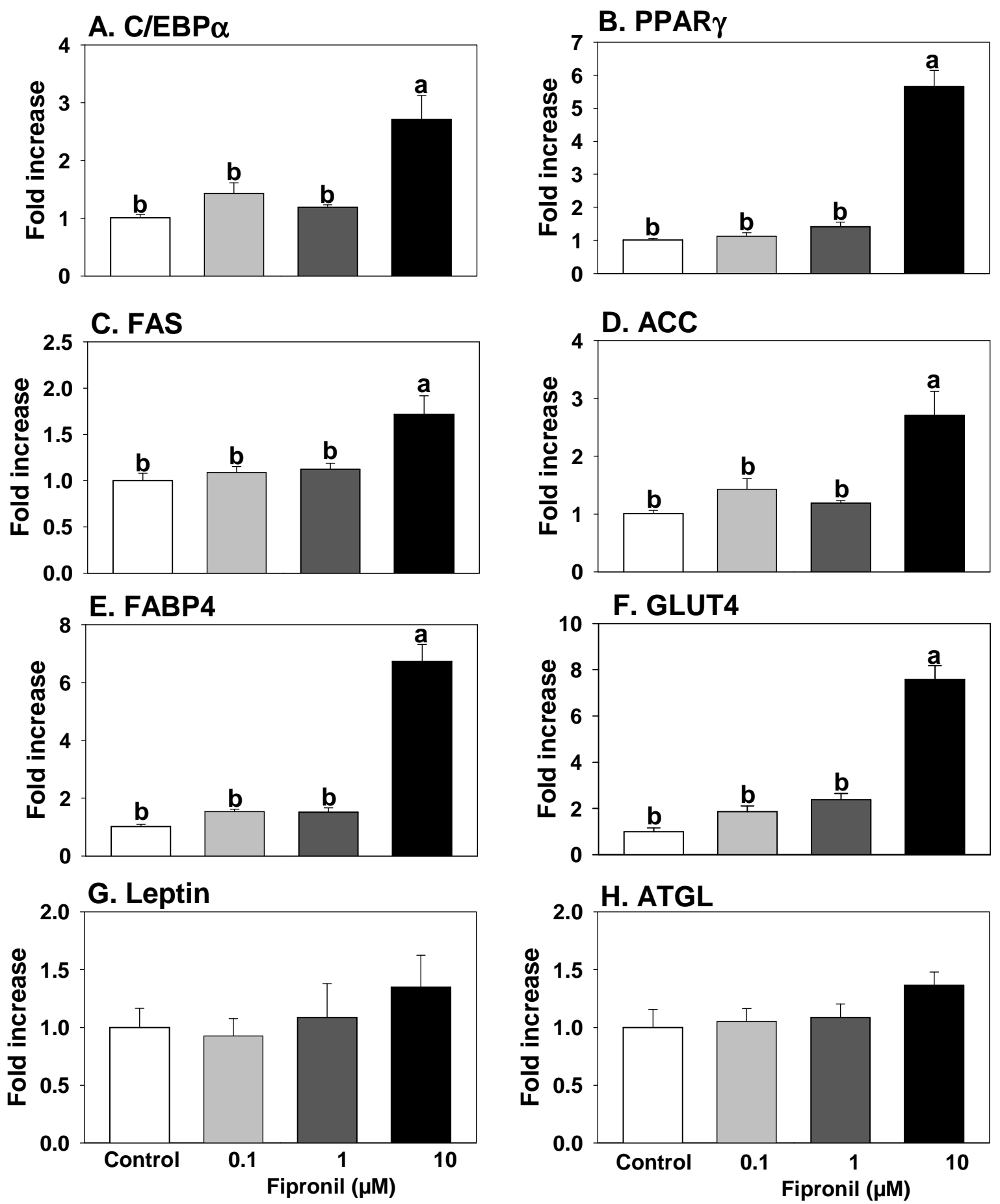
A

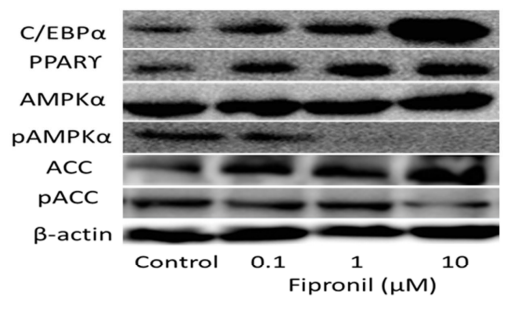

D. AMPK $\alpha$
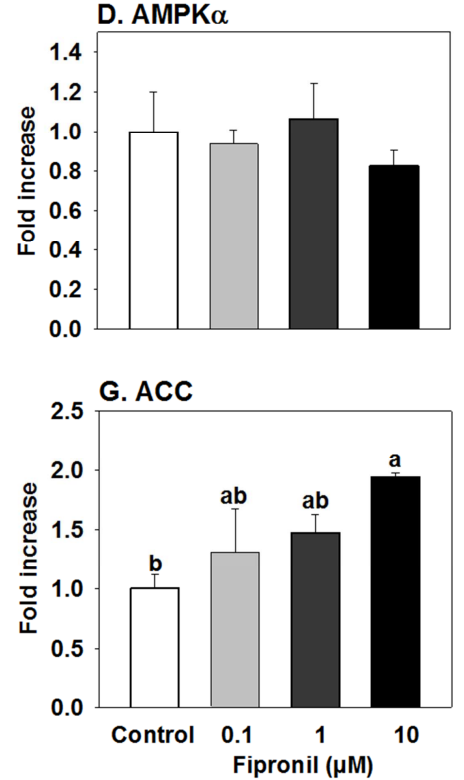

B. C/EBP $\alpha$

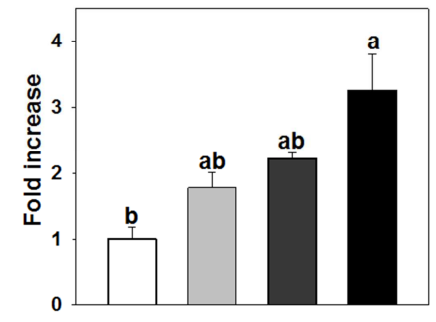

E. pAMPK $\alpha$
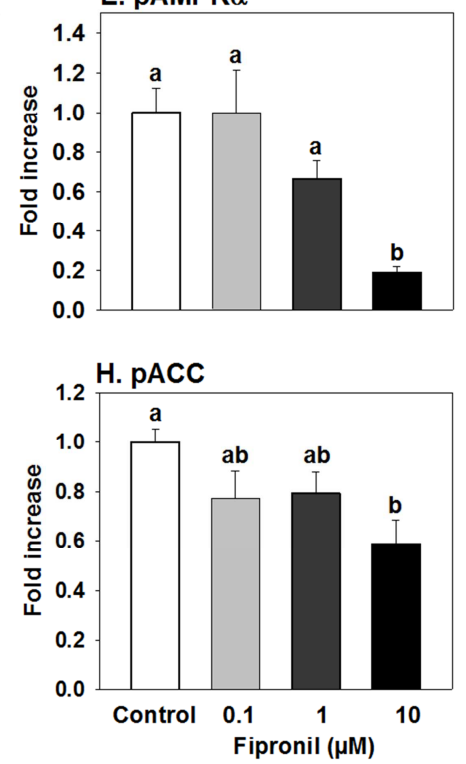

C. PPAR $\gamma$

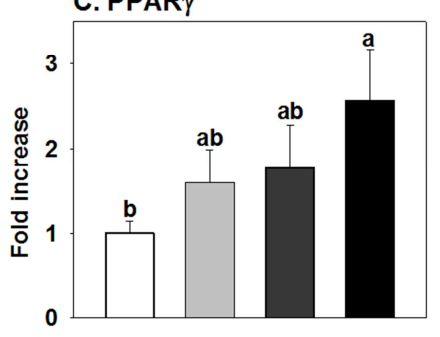

F. pAMPK $\alpha / \mathrm{AMPK} \alpha$
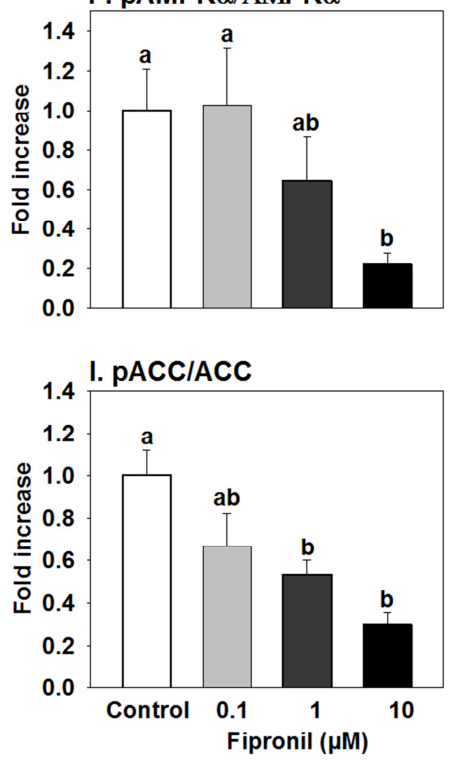


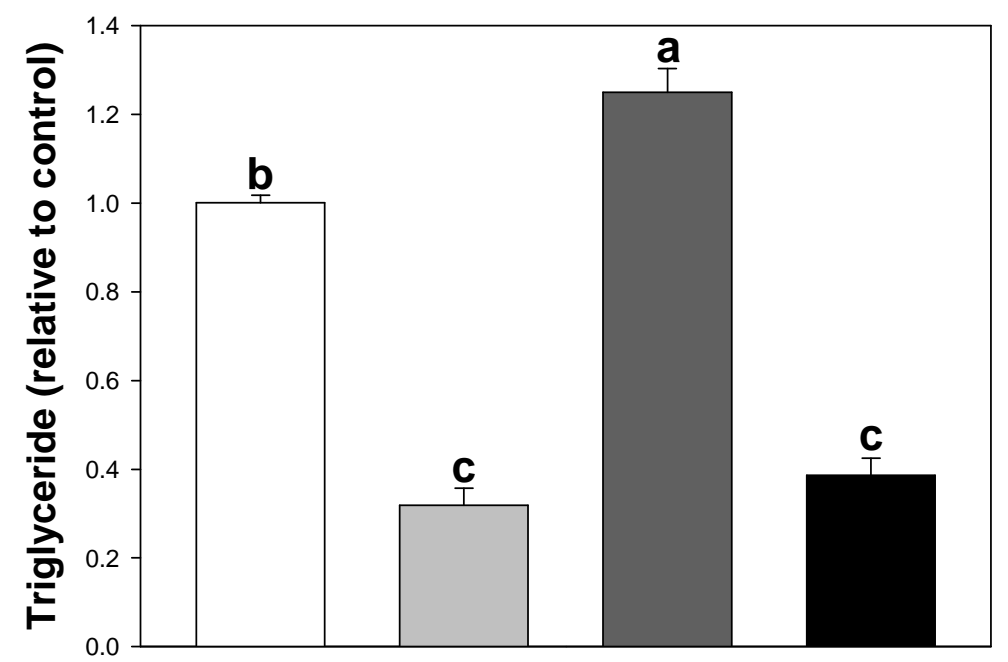

Fipronil

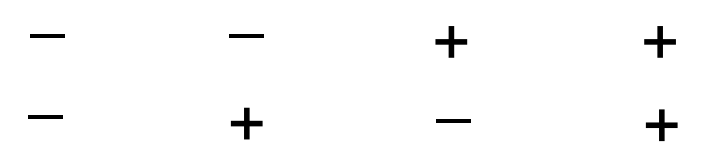


A. C/EBPa AMPKa pAMPKa

ACC

pACC

$\beta$-actin

Fipronil

AICAR

C. $A M P K \alpha$
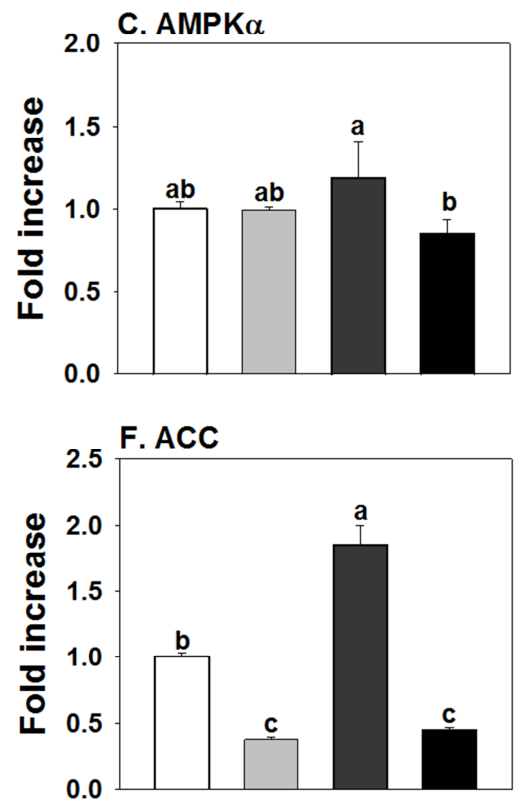
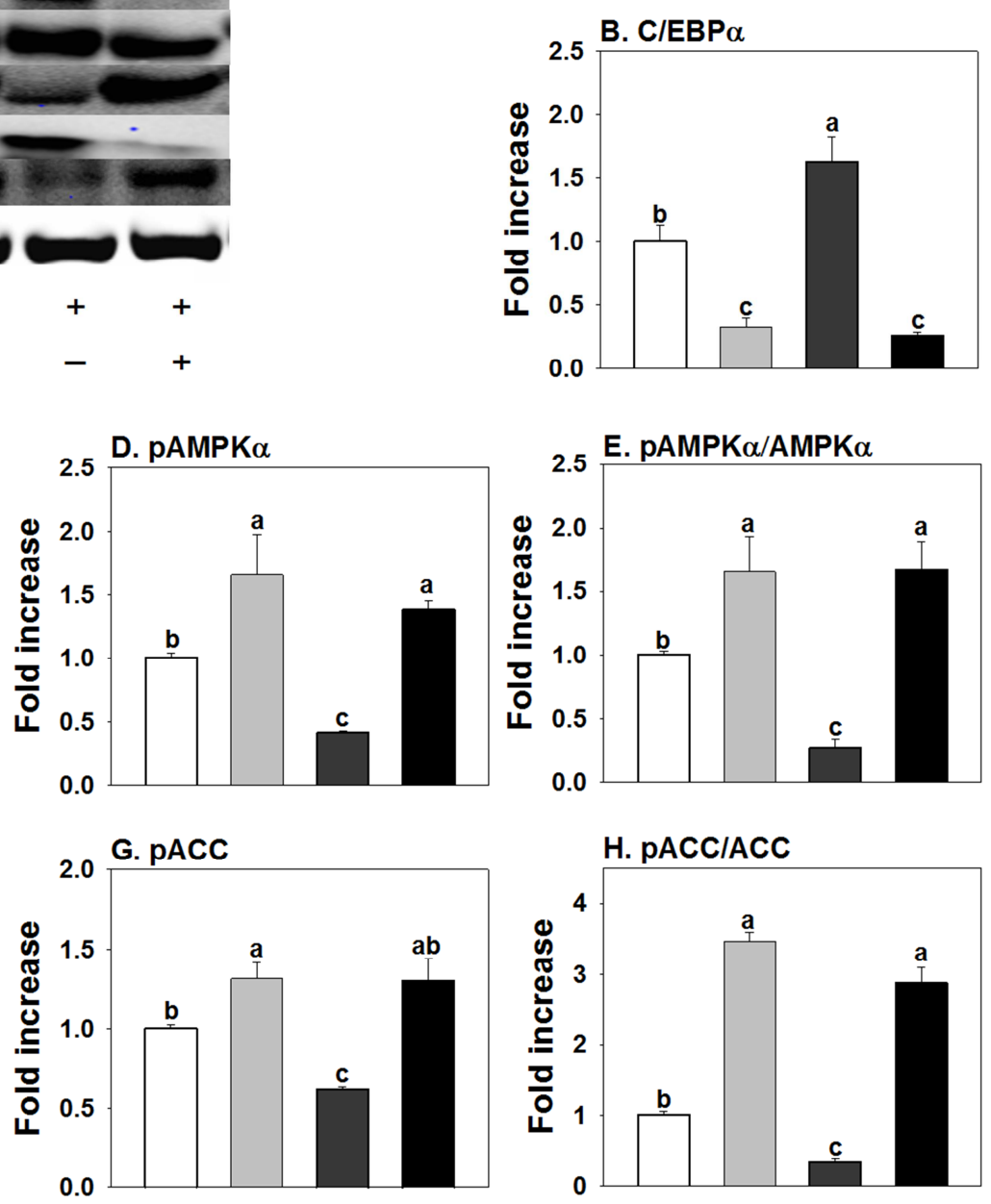

Fipronil $-\quad-\quad+\quad+$ Fipronil $-\quad-\quad+\quad+$ Fipronil $-c_{+}+$

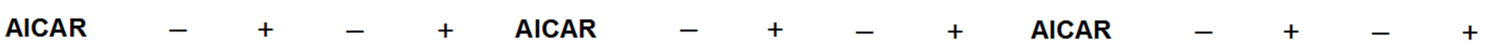


- Fipronil potentiates lipid accumulation in 3T3-L1 adipocytes

- Fipronil stimulates adipocyte differentiation

- Fipronil enhances adipogenesis via AMP-activated protein kinase- $\alpha$ pathway 